\title{
Pengaruh Budaya Kerja Terhadap Hasil Kerja Pegawai Universitas Widya Gama Mahakam Samarinda
}

\author{
Drs.Said Zulkifli. M.Si. \\ Dosen Ilmu Administrasi Negara FISIP UWGM Samarinda
}

\begin{abstract}
Abstrak
Pengembangan sumber daya manusia diyakini merupakan jawaban atas setiap masalah yang terjadi pada setiap tingkatan organisasi. Oleh karena itu sebagai aparatur negara yang bergerak dibidang pendidikan tinggi harus mampu melayani, mengayomi, menumbuhkan prakarsa dan dapat mengimplementasikan apa yang menjadi komitmen selaku aparatur sipil negara, mereka harus memiliki dan menunjukkan integritas, dedikasi, loyalitas, keterampilan, kejujuran, wawasan yang luas dan meningkatkan mutu pekerjaan serta pelayanan. Berdasarkan pengamatan di lokasi penelitian terlihat gejala-gejala mengenai hasil kerja pegawai masih kurang atau belum memenuhi target yang di inginkan. Hal ini dapat dilihat dari lambannya menyelesaikan pekerjaan, sehinga harus menggunakan waktu diluar jam kerja, selain itu waktu yang digunakan dalam jam kerja tidak dimanfaatkan dengan maksimal.

Hasil perhitungan menunjukkan bahwa nilai $\mathrm{t}=4.430$, kemudian jika dibandingkan dengan harga kritis $\mathrm{t}$ tabel untuk $\mathrm{N}-2(30-2=28)$ pada taraf signifikansi 0,05 untuk tes satu sisi nilai $\mathrm{t}$ tabel adalah $4.430>1,701$. Dengan demikian hipotesis yang diajukan dapat diterima yakni diduga Budaya Kerja berpengaruh terhadap Hasil Kerja Pegawai pada Universitas Widya Gama Mahakam Samarinda dan populasi yang sekaligus sebagai sampel telah terbukti mendukung hasil penelitian.
\end{abstract}

Kata kunci: Budaya Kerja, Hasil Kerja, Pegawai Universitas Widya Gama Mahakam Samarinda

\begin{abstract}
Human resource development is believed to be the answer to every problem that occurs at every level of the organization. Therefore, as a state apparatus engaged in higher education must be able to serve, nurture, cultivate initiatives and can implement what is committed as state civil apparatus, they must have and demonstrate integrity, dedication, loyalty, skills, honesty, broad insight and Improve the quality of work and services. Based on the observation at the location of the study seen the symptoms of the work of employees is still lacking or not meet the desired target. This can be seen from the slow completion of the work, so that must use the time outside working hours, other than that the time spent in working hours is not utilized to the maximum.

The calculation results show that the value of $t=4.430$, then when compared with the critical value t table for $N-2(30-2=28)$ at the 0.05 significance level for one - sided test the value of $t$ table is 4.430> 1.701. Thus the proposed hypothesis can be accepted that is suspected Working Culture effect on Employee Results at Widya Gama Mahakam University of Samarinda and the population as well as the sample has been proven to support the results of research.
\end{abstract}


Keywords: Work Culture, Work Results, Employee of Widya Gama Mahakam University of Samarinda

\section{Latar Belakang}

Dalam rangka mencapai tujuan nasional sebagaimana tercantum dalam alinea ke-4 Pembukaan Undang-Undang Dasar Negara Republik Indonesia Tahun 1945 (UUD 1945), diperlukan pegawai ASN yang profesional, bebas dari intervensi politik, bersih dari praktik korupsi, kolusi, dan nepotisme, mampu menyelenggarakan pelayanan publik bagi masyarakat dan mampu menjalankan peran sebagai perekat persatuan dan kesatuan bangsa berdasarkan Pancasila dan UUD NRI 1945.

Untuk mewujudkan tujuan nasional, dibutuhkan Pegawai ASN yang diserahi tugas untuk melaksanakan tugas pelayanan publik, tugas pemerintahan, dan tugas pembangunan tertentu. Tugas pelayanan publik dilakukan dengan memberikan pelayanan atas barang, jasa, dan/atau pelayanan administratif yang disediakan Pegawai ASN. Adapun tugas pemerintahan dilaksanakan dalam rangka penyelenggaraan fungsi umum pemerintahan yang meliputi pendayagunaan kelembagaan, kepegawaian, dan ketatalaksanaan. Sedangkan dalam rangka pelaksanaan tugas pembangunan tertentu dilakukan melalui pembangunan bangsa, pembangunan ekonomi dan sosial yang diarahkan meningkatkan kesejahteraan dan kemakmuran seluruh masyarakat. Tujuan penelitian ini Ingin mengetahui sejauhmana Pengaruh budaya kerja terhadap hasil kerja pegawai pada Universitas Widya Gama Mahakam Samarinda dan menguji kebenaran hipotesis.

\subsection{Rumusan Masalah}

Rumusan masalah dalam penelitian ini adalah "Apakah Budaya Kerja Berpengaruh Terhadap Hasil Kerja Pegawai Pada Universitas Widya Gama Mahakam Samarinda?.

\subsection{Tujuan Penelitian}

Adapun tujuan penelitian ini Ingin mengetahui sejauhmana Pengaruh budaya kerja terhadap hasil kerja pegawai pada Universitas Widya Gama Mahakam Samarinda dan menguji kebenaran hipotesis yang peneliti ajukan serta menguji kemampuan berfikir peneliti dalam menangani masalah.

\section{Kerangka Teori}

\subsection{Budaya Kerja}

Budaya kerja tidak akan muncul bekitu saja akan tetapi harus diupayakan dengan sungguh-sungguh melalui suatu proses yang terkendali dengan melibatkan semua sumber daya manusia dalam seperangkat system, alat-alat dan tekhnik-tekhnik pendukung, budaya kerja merupakan caraa untuk merubah cara kerja lama menjadi cara kerja baru yang berorientasi untuk memuaskan pelanggan dan masyarakat.

Adapun pengertian budaya kerja menurut Supriyadi (2006:8) menyebutkan sebagai berikut "Budaya kerja adalah suatu falsafah yang didasari oleh pandangan hidup sebagai nilai-nilai yang menjadi sifat kebiasaan dan kekuatan pendorong, membudaya dalam kehidupan setau kelompok masyarakat atau organisasi, kemudian tercermin dari sikap dan 
prilaku, kepercayaan, cita-cita loyalitas, pendapat dan tindakan yang terwujud sebagai "kerja" atau "bekerja".

Sedangkan menurut Osborne dan Plastrik (2000:253) "Budaya kerja adalah seperangkat perilaku, perasaan, dan kerangka psikologi yang terinternalisasi sangat mendalam dan dimiliki bersama oleh anggota organisasi'kerja.

Selanjutnya menurut Paramita dalam Supriyadi (2006:10) menyebutkan budaya kerja dapat dibagi menjadi :

a. Sikap terhadap pekerjaan, yaitu kesukaan akan kerja dibandingkan dengan kegiatan lain, seperti bersantai atau semata-mata memperoleh kepuasan dari kesibukan pekerjaan sendiri atau mertasa terpaksa melakukan sesuatu hanya untuk kelangsungan hidupnya.

b. Perilaku pada waktu bekerja, disiplin, berdedikasi. Bertanggung jawab, dan kemauan ya ng kuat untuk mempelajari tugas dan kewajibannya, suka membantu sesame karyawan atau sebaliknya

Berdasarkan pendapat tersebut di atas dapat peneliti simpulkan bahwa budaya kerja adalah merupakan sikap dan prilaku manusia sebagai sebuah kecenderungan untuk bertingkah lakudengan cara-cara tertentu dalam organisasi, karena sikap merupakan bagian dari diri manusia yaitu memiliki kecenderungan dalam melakukan suatu tindakan yang sesuai dengan kondisi perasaan ataupun pengetahuan yang dimilik. Sedangkan perilaku adalah tindakan atau aktivitas dari manusia itu sendiri.

\subsection{Hasil Kerja Pegawai}

Hasil kerja berkaitan dengan pencapain tujuan organisasi pemerintah, maka untuk mengetahui lebih jelas apa yang dimaksud dengan hasil kerja berikut pernyataan beberapa para ahli yang mengemukakan pendapatnya bahwa prestasi kerja merupakan hasil kerja. Oleh karena itu dalam penelitian ini peneliti akan mengutip pendapat para ahli tersebut yang menyatakan bahwa prestasi kerja merupakan hasil kerja, karena dari beberapa buku yang peneliti baca semuanya menyebut prestasi kerja yang disamakan dengan hasil kerja.

Menurut Hasibuan (2000:105) "Prestasi kerja adalah suatu hasil kerja yang dicapai seseorang dalam melaksanakan tugas-tugas yang dibebankan kepadanya yang didasarkan atas kecakapan, pengalaman dan kesungguhan serta waktu. Prestasi kerja merupakan gabungan dari tiga faktor penting yaitu : kemampuan dan minat seorang pekerja, kemampuan dan penerimaan atas penjelasan delegasi tugas serta peran dan tingkat motivasi seorang pekerja.

Kemudian menurut Mangkunegara (2000:67) mengatakan bahwa "Prestasi kerja adalah hasil kerja secara kualitas, kuantitas dan yang dicapai oleh seorang pegawai dalam melaksanakan tugasnya sesuai dengan tanggung jawab yang diberikan kepadanya".

Dari pengertian di atas dapat disimpulkan bahwa prestasi kerja adalah hasil kerja yang dicapai oleh seseorang dalam melaksanakan tugas yang diberikan kepadanya sesuai dengan kriteria atau standar yang ditetapkan. Hasil kerja pegawai dapat dilihat dari kemampuan, perangai serta minat pegawai tersebut terhadap pekerjaan. Berbicara hasil kerja maka erat kaitannya dengan masalah kualitas sumber daya manusia atau lebih cepatnya kualitas pegawai. Kualitas pegawai dapat dilihat dari ketelitian, keterampilan, kemampuan, kebersihan pekerjaan, inisiatif, kreativitas, ketegasan, ketepan dalam menjalankan tugas dan tanggung jawab. 


\subsection{Hipotesis}

Adapun hipotesis yang dikemukakan dalam penelitian ini, yakni diduga Budaya Kerja berpengaruh terhadap Hasil Kerja Pegawai pada Universitas Widya Gama Mahakam Samarinda sebagai Hipotesis Ha, dan diduga Budaya Kerja tidak berpengaruh terhadap Hasil Kerja Pegawai pada Universitas Widya Gama Mahakam Samarinda sebagai Hipotesis Ho.

\subsection{Definisi Oeprasional}

Adapun definisi operasional yakni Budaya Kerja Pegawai dengan indikator Sikap terhadap pekerjaan, Tanggung jawab kerja pegawai, dan Loyalitas para pegawai sedangkan Hasil kerja pegawai dengan indikator Pengalaman dalam bekerja, Kesungguhan dalam bekerja, dan Waktu penyelesaian pekerjaan.

\section{Metodologi}

\subsection{Jenis Penelitian}

Berdasarkan definisi di atas maka jenis penelitian yang dihadapi peneliti adalah verifikatif atau causalitas. Yaitu suatu penelitian yang mencari hubungan sebab akibat diantara dua variabel yang sedang diselidiki.

\subsection{Populasi dan Sampel}

Seluruh pegawai sebagai tenaga kependidikan yang ada pada Universitas Widya Gama Mahakam Samarinda yang berjumlah sebanyak 60 orang pegawai mengingat jumlah populasi yang terlalu banyak maka peneliti mengambil sampel sebesar $50 \%$ dengan cara simple random sampling yaitu dengan cara mengacak seluruh populasi sehingga didapatlah 30 orang responden. Dengan dua macam gejala yaitu gejala nominal dan gejala kontinum dan menggunakan jenjang $5(1,2,3,4,5)$ dengan nilai sebagai berikut :

1. Apabila responden menjawab a maka akan diberi nilai 5

2. Apabila responden menjawab b maka akan diberi nilai 4

3. Apabila responden menjawab c maka akan diberi nilai 3

4. Apabila responden menjawab d maka akan diberi nilai 2

5. Apabila responden menjawab e maka akan diberi nilai 1

\subsection{Tekhnik Analisis Data}

Alat analisis data yang penulis gunakan dalam penelitian ini adalah alat analisis koefisien korelasi Rank Spearman dari Sidney Siegel (1996:253) yang rumusnya sebagai berikut :

$$
r s=\frac{\sum x^{2}+\sum y^{2}-\sum d_{i}^{2}}{2 \sqrt{ } \sum x^{2} \cdot \sum y^{2}}
$$

Dimana :

$$
\begin{aligned}
& \sum \mathrm{x}^{2}=\frac{\mathrm{N}^{3}-\mathrm{N}}{12}-\sum \mathrm{T} \mathrm{x} \\
& \sum \mathrm{y}^{2}=\frac{\mathrm{N}^{3}-\mathrm{N}}{12}-\sum \mathrm{Ty}
\end{aligned}
$$


Kemudian untuk mengoreksi jumlah kuadrat dengan mempertimbangkan angka sama, maka penulis akan menggunakan faktor koreksi $\mathrm{T}$, dengan rumus sebagai berikut:

$$
\mathrm{T}=\frac{\mathrm{t}^{3}-\mathrm{t}}{12}
$$

Keterangan :

$\Upsilon_{\mathrm{s}} \quad=$ koefisien korelasi Rank Spearman

$\sum \mathrm{x}^{2}=$ jumlah kudrat variabel $\mathrm{x}$

$\sum \mathrm{y}^{2}=$ Jumlah kuadrat variabel $\mathrm{y}$

$\sum \mathrm{di}^{2}=$ jumlah kuadrat hasil selisih ranking $\mathrm{x}$ dan $\mathrm{y}$

$\mathrm{n} \quad=$ jumlah responden yang diambil.

$\mathrm{T}=$ faktor koreksi bagi angka sama

$\mathrm{n} \quad=$ jumlah variabel yang mempunyai angka sama

12 = bilangan tetap

Dengan demikian dapat diketahui apabila koefisien korelasi yang diperoleh lebih besar dari Ys tabel dengan tingkat signifikansi 0,05 untuk uji satu sisi, maka dapat disimpulkan bahwa terdapat pengaruh yang positif diantara kedua variabel. Akan tetapi jika sebaliknya bahwa $\Upsilon_{s}$ tabel lebih besar dari $\Upsilon_{s}$ empiris untuk tes satu sisi, maka hipotesis yang diajukan ditolak.

\section{Analisi dan Hasil Penelitian}

\subsection{Analisis}

Peneliti menggunakan rumus koefisien korelasi Rank Spearman dengan langkahlangkah sebagai berikut :

a. Memberikan ranking pada observasi variabel (X) dan variabel $(\mathrm{Y})$ berdasarkan nilai mentah dengan mengelompokkan skor yang berangka sama mulai dari yang terendah sampai yang tertinggi.

b. Menentukan harga $\mathrm{d}_{\mathrm{i}}$ untuk setiap subyek dengan cara mengurangkan ranking $(\mathrm{X})$ pada ranking (Y).

c. Masing-masing subyek dikuadratkan untuk memperoleh $\mathrm{d}_{\mathrm{i}}^{2}$ pada setiap subyek

d. Harga-harga $\mathrm{d}_{\mathrm{i}}{ }^{2}$ dijumlah untuk 30 kasus guna mendapatkan $\sum \mathrm{d}_{\mathrm{i}}{ }^{2}$ demikian juga dengan ranking $\mathrm{X}, \mathrm{Y}$ dan $\mathrm{d}_{\mathrm{i}}$.

e. Menentukan $\sum \mathrm{x}^{2}$ dan $\sum \mathrm{y}^{2}$ dengan menunjukkan rumus setelah diketahui ranking yang berangka sama pada masing-masing variabel, maka digunakan faktor koreksi dengan simbol $\mathrm{T}$, dimana $\mathrm{T}$ tersebut digunakan untuk mendapatkan $\sum \mathrm{x}^{2}$ dan $\sum \mathrm{y}^{2}$.

f. Selanjutnya mencari harga $\Upsilon$ s empiris dengan menggunakan rumus dan kemudian diadakan pengujian hipotesis dengan membandingkan harga $\Upsilon_{s}$ empiris dengan rs tabel pada tingkat signifikansi 0,05 untuk tes satu sisi. 
Setelah didapat harga $\Upsilon_{s}$ empiris, kemudian untuk mengoreksi lebih lanjut hasil antara independen variabel dan dependen variabel, maka diadakan uji $t$ untuk mengetahui pengaruh antara kedua variabel dengan tabel sebagaimana terlampir.

Berdasarkan tabel terlampir, diketahui bahwa pada variabel budaya kerja (x) terdapat 5 (lima) himpunan berangka sama, yaitu terdiri dari :

3 subyek yang berangka sama pada skor 9 diberi ranking 2

8 subyek yang berangka sama pada skor 10 diberi ranking 7,5

4 subyek yang berangka sama pada skor 11 diberi ranking 13,5

11 subyek yang berangka sama pada skor 12 diberi ranking 21

4 subyek yang berangka sama pada skor 13 diberi ranking 28,5

Kemudian pada variabel hasil kerja pegawai terdapat 4 (empat) himpunan berangka sama, yaitu terdiri dari

5 subyek yang berangka sama pada skor 10 diberi ranking 3

6 subyek yang berangka sama pada skor 11 diberi ranking 8,5

10 subyek yang berangka sama pada skor 12 diberi ranking 16,5

13 subyek yang berangka sama pada skor 16 diberi ranking 25,5

Untuk menganalisis data dan pengujian hipotesis peneliti menggunakan rumus "Koefisien Korelasi Rank Spearman" adapun perhitungannya sebagai berikut :

$$
\begin{aligned}
& \sum \mathrm{x}^{2}=\frac{\mathrm{N}^{3}-\mathrm{N}}{12}-\sum \mathrm{Tx} \\
& \sum \mathrm{y}^{2}=\frac{\mathrm{N}^{3}-\mathrm{N}}{12} \quad-\sum \mathrm{Ty} \\
& \mathrm{T}=\frac{\mathrm{t}^{3}-\mathrm{t}}{12} \\
& \sum \mathrm{x}^{2}=\frac{30^{3}-30}{12}-\frac{3^{3}-3}{12}+\frac{8^{3}-8}{12}+\frac{4^{3}-4}{12}+\frac{11^{3}-11}{12} \\
& 4^{3}-4
\end{aligned}
$$




$$
\begin{aligned}
& =\frac{26970}{12}-\frac{24}{12}+\frac{504}{12}+\frac{60}{12}+\frac{1320}{} \\
& =2247,5-2+42+5+110 \\
& =2247,5-159 \\
& \sum \mathbf{x}^{2}=208,85 \\
& \sum y^{2}=\frac{30^{3}-30}{12}-\frac{5^{3}-5}{12}+\frac{6^{3}-6}{1212}+\frac{10^{3}-10}{12}+8^{3}-8 \\
& =\frac{26970}{12}-\frac{120}{12}+\frac{210}{12}+\frac{990}{12} \quad \frac{504}{12} \\
& =2247,5-10+17,5+82,5+42 \\
& =2247,5-152 \\
& \sum \mathbf{y}^{2}=209,55
\end{aligned}
$$

Dengan telah diketahuinya $\sum \mathrm{x}^{2}, \sum \mathrm{y}^{2}$ dan $\sum \mathrm{d}_{\mathrm{i}}{ }^{2}$ maka dapatlah dioperasikan rumus koefisien korelasi Rank Spearman, sebagai berikut

$$
\begin{aligned}
& \Upsilon_{s}=2 \frac{\sum \mathrm{x}^{2}+\sum \mathrm{y}^{2}-\sum \mathrm{d}_{\mathrm{i}}^{2}}{\sqrt{ } \frac{\sum \mathrm{x}^{2} \cdot \sum \mathrm{y}^{2}}{2}} \\
& =\frac{208,85+209,55-1268,5}{2 \sqrt{208,85 \cdot 1268,5}} \\
& =2 \sqrt{\frac{850}{4376}} \\
& =\frac{850}{2 \cdot 661,5} \\
& =\quad \frac{850}{1323} \quad=\quad \mathbf{0 , 6 4 2}
\end{aligned}
$$


Dari hasil perhitungan tersebut, dapat diketahui bahwa koefisien korelasi antara budaya kerja dengan hasil kerja pegawai adalah 0,642. Kemudian jika dibandingkan dengan harga $\Upsilon_{\mathrm{s}}$ kritis tabel untuk $\mathrm{N}=30$ nilainya 0,306 untuk tes satu sisi, ini berarti $\Upsilon$ s hitung atau $\Upsilon \mathrm{s}$ empiris lebih besar dari $\Upsilon_{s}$ tabel pada taraf signifikansi 0,05. Dengan demikian terdapat pengaruh yang positif antara budaya kerja dan hasil kerja pegawai . Dengan demikian maka hipotesis alternatif yang diterima kebenarannya dan menolak hipotesis null.

\subsection{Pengujian Hipotesis}

Selanjutnya untuk menguji apakah budaya kerja berpengaruh terhadap hasil kerja untuk responden 30 orang maka perlu dilakukan koreksi lebih lanjut yaitu dengan melakukan uji t dengan perhitungan sebagai berikut :

$$
\begin{aligned}
& \mathrm{t}=\Upsilon \mathrm{s} \sqrt{\mathrm{N}-2} \frac{\mathrm{N} \mathrm{s}^{2}}{1-} \\
& =0.642 \sqrt{ }^{30-2} \\
& 1-(0,642)^{2} \\
& =0,642 \quad \frac{28}{1-0,412164} \\
& =0,642 \quad \frac{28}{0,587836} \\
& =0,642 \quad \sqrt{ } \quad 47.632332 \\
& =0,642.6 .901618 \\
& \mathrm{t}=4,430
\end{aligned}
$$

Hasil perhitungan di atas, dapat diketahui bahwa nilai $\mathrm{t}=4.430$, kemudian jika dibandingkan dengan harga kritis $\mathrm{t}$ tabel untuk $\mathrm{N}-2(30-2=28)$ pada taraf signifikansi 0,05 untuk tes satu sisi nilai $t$ tabel adalah $4.430>1,701$. Dengan demikian hipotesis yang diajukan dapat diterima dan populasi yang sekaligus sebagai sampel telah terbukti mendukung hasil penelitian.

\section{Simpulan dan Saran}

\subsection{Simpulan}

Berdasarkan hasil penelitian yang telah dilakukan pada Universitas Widya Gama Mahakam Samarinda dapat peneliti simpulkan sebagai berikut: 
1. Terdapat pengaruh yang positif antara variabel budaya kerja terhadap hasil kerja yang diperoleh dari hasil perhitungan rs empiris untuk $\mathrm{N}=30$ sebesar 0,642 yang ternyata lebih besar dari rs tabel harga-harga kritis rs koefisien korelasi Rank Spearman yaitu 0,306 pada tingkat signifikansi 0,05 untuk tes satu sisi.

2. Selanjutnya dilakukan pengujian hipotesis dengan nilai t hitung $=4,430$, kemudian dibandingkan dengan harga kritis $t$ tabel untuk $\mathrm{N}-2(30-2=28)$ pada taraf signifikansi 0,05 nilai $\mathrm{t}$ tabel adalah 1,701. Dengan demikian hipotesis yang diajukan dapat diterima dan populasi yang sekaligus sebagai sampel telah terbukti mendukung hasil penelitian, karena t hitung lebih besat dari t tabel 4,430 >1,701.

3. Dengan terbuktinya kebenaran hipotesis yang telah peneliti rumuskan, maka jelaslah bahwa budaya kerja yang baik yang dilakukan oleh para pegawai Universitas Widya Gama Mahakam Samarinda.

4. akan mempengaruhi hasil kerja pegawai dalam melaksanakan tugas pekerjaan yang diembannya.

5. Berdasarkan hasil perhitungan untuk variabel budaya kerja dan hasil kerja pegawai, maka dapat dilihat bahwa para pegawai mempunyai upaya untuk dapat meningkatkan hasil kerjanya sesuai dengan kemampuan dan tanggung jawab masing-masing bidang tugasnya.

\subsection{Saran} berikut:

Adapun saran-saran yang peneliti ajukan dalam penulisan skripsi ini adalah sebagai

1. Untuk mencapai tujuan yang telah ditetapkan, khususnya pada para pegawai Universitas Widya Gama Mahakam Samarinda hendaknya selalu memperhatikan hasil kerja pegawai dengan jalan membudayakan kerja kepada pegawai yang baik, sehingga tercipta hubungan yang selaras, serasi dan seimbang serta harmonis.

2. Agar budaya kerja dapat terus ditingkatkan, maka diperbanyak frekuensi pertemuan formal dan informal antara pimpinan dan bawahan, antar pimpinan dan antar bawahan serta teladan yang baik dari pimpinan

3. Agar pelaksanaan budaya kerja dan hasil kerja pegawai dapat berjalan dengan baik, maka kemampuan dan keterampilan pegawai dilingkungan Universitas Widya Gama Mahakam Samarinda perlu mendapat peningkatan lagi dengan melalui jalur pendidikan dan latihan yang sesuai dengan bidang tugas masing-masing.

4. Untuk meningkatkan hasil kerja pegawai hendaknya pihak pimpinan memperhatikan juga faktor-faktor lain selain budya kerja, karena masih banyak lagi hal-hal lainnya yang dapat mempengaruhi hasil kerja pegawai. 


\section{Lampiran}

Tabel Nilai dan ranking persiapan data dari variabel budaya kerja dan hasil kerja pegawai pada Universitas Widya Gama Mahakam Samarinda.

\begin{tabular}{|c|c|c|c|c|c|c|}
\hline \multirow[t]{2}{*}{ Responden } & \multicolumn{2}{|c|}{ S k o r } & \multicolumn{2}{|c|}{ Ranking } & \multirow[t]{2}{*}{$\mathrm{d}_{\mathrm{i}}$} & \multirow[t]{2}{*}{$\mathrm{d}_{\mathrm{i}}^{2}$} \\
\hline & $X$ & $\mathrm{Y}$ & $\mathrm{X}$ & $\mathrm{y}$ & & \\
\hline 1 & 2 & 3 & 4 & 5 & 6 & 7 \\
\hline 01 & 10 & 11 & 7,5 & 8,5 & -1 & 1 \\
\hline 02 & 12 & 11 & 21 & 8,5 & 12.5 & 156,25 \\
\hline 03 & 12 & 12 & 21 & 16,5 & 4,5 & 20,25 \\
\hline 04 & 9 & 10 & 2 & 3 & -1 & 1 \\
\hline 05 & 10 & 10 & 7,5 & 3 & 4,5 & 20,25 \\
\hline 06 & 12 & 11 & 21 & 8,5 & 12,5 & 156,25 \\
\hline 07 & 12 & 12 & 21 & 16,5 & 4,5 & 20,25 \\
\hline 08 & 11 & 12 & 13,5 & 16,5 & -3 & 9 \\
\hline 09 & 10 & 10 & 7,5 & 3 & 4,5 & 20,25 \\
\hline 10 & 10 & 11 & 7,5 & 8,5 & $\begin{array}{ll}- & 1\end{array}$ & 1 \\
\hline 11 & 10 & 10 & 7,5 & 3 & 4,5 & 20,25 \\
\hline 12 & 12 & 12 & 21 & 16,5 & 4,5 & 20,25 \\
\hline 13 & 10 & 12 & 7,5 & 16,5 & -9 & 81 \\
\hline 14 & 9 & 11 & 2 & 8,5 & - $\quad 6,5$ & 42,25 \\
\hline 15 & 13 & 13 & 28,5 & 25,5 & 3 & 9 \\
\hline 16 & 9 & 11 & 2 & 8,5 & - $\quad 6,5$ & 42,25 \\
\hline 17 & 12 & 12 & 21 & 16,5 & 4,5 & 20,25 \\
\hline 18 & 11 & 12 & 13,5 & 16,5 & -3 & 9 \\
\hline 19 & 11 & 13 & 13,5 & 25,5 & $\begin{array}{ll}-\quad 12 \\
\end{array}$ & 144 \\
\hline 20 & 10 & 10 & 7,5 & 3 & 4,5 & 20,25 \\
\hline 21 & 12 & 13 & 21 & 25,5 & - 4,5 & 20,25 \\
\hline 22 & 10 & 13 & 7,5 & 25,5 & $\begin{array}{ll}- & 18\end{array}$ & 324 \\
\hline 23 & 12 & 12 & 21 & 16,5 & 4,5 & 20,25 \\
\hline 24 & 12 & 13 & 21 & 25,5 & - 4,5 & 20,25 \\
\hline 25 & 12 & 13 & 21 & 25,5 & $-4,5$ & 20,25 \\
\hline
\end{tabular}




\begin{tabular}{|c|c|c|c|c|c|c|}
\hline 26 & 13 & 13 & 28,5 & 25,5 & 3 & 9 \\
\hline 27 & 13 & 14 & 28,5 & 30 & $-1,5$ & 2,25 \\
\hline 28 & 12 & 12 & 21 & 16,5 & 4,5 & 20,25 \\
\hline 29 & 13 & 13 & 28,5 & 25,5 & 3 & 9 \\
\hline 30 & 11 & 12 & 13,5 & 16,5 & -3 & 9 \\
\hline Jumlah & & & & & 0 & 1268,5 \\
\hline
\end{tabular}

Sumber Data : Hasil jawaban responden

Daftar Pustaka

AGUS DHARMA, 2000, Manajemen produksi, Penerbit Fakultas Ekonomi, Universitas Indonesia, Jakarta

ANONIM, 2014, Undang-Undang Republik Indonesia Nomo5 Tahun 2014, Tentang Aparatur Sipil Negara, Jakarta.

MUHAMMAD THOHA, 2003, Prilaku Organisasi, Penerbit, Gramedia, Jakarta.

FAISAL TAMIM, 2007, Tranformasi Budaya Kerja Aparatur Negara Penerbit PKP2AIII Lan Samarinda

HADARI NAWAWI, 2000, Metodologi Penelitian Bidang Sosial, Penerbit Gajah Mada University Press, Yogyakarta.

HASIBUAN, 2000, Manajemen Sumber Daya Manusia, Edisi Revisi, Penerbit Bina Aksara, Jakarta.

KARTINI KARTONO, 1999, Pengantar Metodologi Research, Penerbit Alumni, Bandung.

KOENTJARANINGRAT, 1999, Metode-metode Penelitian Masyarakat, Penerbit Gramedia, Jakarta.

LAN, 2004, Dari Budaya Kerja Menuju Kinerja Organisasi, Penerbit Kelompok Budaya Kerja PKP2A III LAN. Samarinda

MANGKUNEGARA, 2000, Manajemen Sumber Daya Manusia Perusahaan, Penerbit Rosdakarya, Bandung

MASRI SINGARIMBUN DAN SOFIAN EFFENDI, 1999, Metode Penelitian Survai, Penerbit LP3ES, Jakarta.

MUHAMMAD AS'AD,2000, Seni Ilmu Manajemen Sumber Daya Manusia, Penerbit Liberty. Yogyakarta

MUNZIR, 2009, Pengembangan Budaya Kerja, Penerbit, Kemenag, Jakarta

H. NAINGGOLAN, 1999, Pembinaan Pegawai Negeri Sipil, Penerbit Pertja, Jakarta.

OSBORN DAN PLASTRIK, 2000, Memangkas Birokrasi, Penerbit PPM. Jakarta

PARIATA WESTRA, 1999, Ensiklopedia Administrasi,, Penerbit Gunung Agung, Jakarta.

WUKIR RAGIL, 2010, Budaya Kerja Kemendiknas Republik Indonesia, Jakarta

ROBBINS P. STEPHAN, 1999, Teori OrganisasiStruktur Disain dan Aplikasi Penerbit Arcan, Jakarta

RICHARD M. STERS, 1996, Efektivitas, Penerbit PT. Tarsito, Bandung

RYAN IRTANTO, 2013, Diponegoro Journal Of Social And Politic Tahun 2013, Hal. 1-9 http://ejournal- s1.undip.ac.id/index.php (diakses 4 Agustus 2015)

SIDNEY SIEGEL, 1996, Statistik Nonparametrik Untuk Ilmu-ilmu Sosial, Penerbit PT. Gramedia, Jakarta. 
SOERJONO SOEKANTO, 2002, Sosiologi Suatu Pengantar, yayasan Penerbit Universitas Indonesia, Jakarta.

SUGIYONO, 2004, Metode Penelitian Administrasi, Penerbit Alfabetha, Bandung

SONDANG P. SIAGIAN, 1999, Manajemen Sumber Daya Manusia, Penerbit Bina Aksara, Jakarta

SUPRIYADI, 2006, Budaya Kerja Organisasi Pemerintahan, Modul Dilat Pejabat Golongan III, Penerbit LAN. Jakarta

SUTRISNO HADI, 2004, Metodologi Research Jilid I dan III, Penerbit Andi Offcet, Yogyakarta.

SYARIF MUHIDIN, 2001, Pengantar Kesejahteraan Sosial, Penerbit Sekolah Kesejahteraan, Bandung.

T. HANNY HANDOKO, 2004, Manajemen Personalia dan Sumber Daya Manusia, Penerbit BPFE. Yogyakarta

USMAN DAN AKBAR, 2003, Metode Penelitian Sosial, Penerbit Bumi Aksara, Jakarta

USMAN TAMPUBOLON, 1990, Metode Penelitian Administrasi, Penerbit BPA. UGM. Yogyakarta.

WINARNO SURACHMAD, 1999, Dasar-dasar Tekhnik Research Pengantar Metodologi Ilmiah, Penerbit CV. Tarsito, bandung. 